\title{
Influência da governança corporativa na evidenciação voluntária de informações de natureza socioambiental
}

\section{Influence of corporate governance on the voluntary evidence of socio-environmental information}

\author{
SADY MAZZIONI* \\ CLÁUDIA MARA COFSEVICZ** \\ GEOVANNE DIAS DE MOURA***
}

FRANCISCA FRANCIVÂNIA RODRIGUES RIBEIRO MA$C \hat{E} D O^{* * * *}$

SILVANA DALMUTT KRÜGER****

\section{RESUMO}

O objetivo do estudo é analisar a influência da governança corporativa na evidenciação voluntária de natureza socioambiental em empresas familiares e não familiares listadas na BM\&FBovespa. A pesquisa é natureza descritiva, documental e quantitativa, realizada com uma amostra de 64 empresas que divulgaram o relatório de sustentabilidade no modelo GRI 2014. A evidenciação socioambiental voluntária foi analisada por meio de um constructo composto por 150 indicadores das dimensões econômica, ambiental e social. Como proxy para a governança corporativa foi utilizado o Índice de Ações com Governança Corporativa Dife-

* Universidade Comunitária da Região de Chapecó - UNOCHAPECÓ. Doutor em Ciências Contábeis e Administração - FURB. sady@unochapeco.edu.br

** Universidade Comunitária da Região de Chapecó - UNOCHAPECÓ. Bacharel em Ciências Contábeis na Universidade Comunitária da Região de Chapecó - UNOCHAPECÓ. claudiacofsevicz@unochapeco.edu.br

*** Universidade Comunitária da Região de Chapecó - UNOCHAPECÓ. Doutor em Ciências Contábeis e Administração - FURB. geomoura@terra.com.br

**** Universidade Estadual Vale do Acaraú - UVA. Doutora em Ciências Contábeis e Administração - FURB. francymacedo2011@gmail.com

**** Universidade Comunitária da Região de Chapecó - UNOCHAPECÓ. Doutoranda em Contabilidade - UFSC.silvanak@unochapeco.edu.br 
renciada (IGCX) da BM\&FBovespa. Os resultados revelaram que a dimensão econômica possui um número superior de informações divulgadas e que as empresas não familiares apresentaram média de evidenciação mais elevada. A variável governança corporativa não apresentou significância estatística, diferente do esperado e contrariando constatações de estudos internacionais. Conclui-se que no Brasil, em razão de o mercado de ações ainda estar em desenvolvimento e a maioria das companhias possuir propriedade altamente concentrada, a pressão exercida pelo acionista controlador pode estar reduzindo o impacto positivo das práticas de governança corporativa na evidenciação socioambiental voluntária.

Palavras chave: Governança corporativa; evidenciação voluntária; socioambiental.

\section{Abstract}

The objective of the study is to analyze the influence of corporate governance on the voluntary disclosure of socioenvironmental nature in family and non-family companies listed on BM\&FBovespa. The research is descriptive, documental and quantitative, carried out with a sample of 64 companies that published the sustainability report in the GRI 2014 model. The voluntary socioenvironmental disclosure was analyzed through a construct composed of 150 indicators of the economic, environmental and social dimension. As a proxy for corporate governance, the BM\&FBovespa's Differentiated Corporate Governance Stock Index (IGCX) was used. The results revealed that the economic dimension has a higher number of information disclosed and non-family companies presented a higher average of disclosure. The variable corporate governance did not present statistical significance, different from the one expected and contrary to findings of international studies. It is concluded that in Brazil, because the stock market is still in development and most companies have highly concentrated ownership, the pressure exerted by the controlling shareholder may be reducing the positive impact of corporate governance practices on voluntary socioenvironmental disclosure.

Keywords: Corporate governance; voluntary evidence; socioenvironmental. 


\section{INTRODUÇÃo}

A inclusão de práticas de responsabilidade socioambiental tem caracterizado o comportamento de empresas mais integradas e preocupadas com o desempenho organizacional. Essas práticas, quando exercidas nas três dimensões da sustentabilidade corporativa (econômica, ambiental e social) podem proporcionar benefícios expressivos às organizações (ROMANO, 2014).

No que se refere às práticas ambientais, por exemplo, a evidenciação voluntária de informações de natureza socioambiental (green reporting ou disclosure verde) difere do escopo tradicional da contabilidade, focado nas demonstrações contábeis (ROVER et al., 2008). Porém, os eventos socioambientais podem ter implicações nas medidas de desempenho econômico-financeiro ou até mesmo no valor da empresa e, portanto, a informação contábil socioambiental é relevante (LIU; ZHANG, 2017).

As corporações têm percebido que, mais do que respeitar a legislação, precisam adotar práticas ecologicamente corretas no processo produtivo. Dessa forma, para que sobrevivam no mercado, não é suficiente apenas ser economicamente lucrativas, mas, necessitam também ser ecologicamente corretas e se preocupar com a sociedade na qual estão inseridas (PEREIRA et al., 2016; TAN; HABIBULLAH; TAN, 2017).

A partir desse cenário, a evidenciação de informações socioambientais vem contribuindo para que as empresas consigam manter a comunicação sobre a gestão ambiental com as diversas partes interessadas (stakeholders) como órgãos reguladores, governamentais, sociedade civil organizada, comunidade científica, investidores, credores, fornecedores e clientes (FREEDMAN; JAGGI, 1988; BERNARDI; STARK, 2016).

Liu e Zhang (2017) mencionam que a relação da empresa com esses diversos públicos pode ser melhorada por meio da adoção de boas práticas de governança corporativa. Destacam ainda que a governança corporativa coordena as relações entre os grupos cujos interesses podem entrar em conflito para evitar abusos de poder e comportamentos ilegais. Desse modo, a qualidade e a eficiência da tomada de decisões das empresas podem ser melhoradas, os custos de transações e de agência reduzidos ou controlados, os interesses 
dos investidores ou partes interessadas protegidos e o máximo valor corporativo alcançado. Assim, Liu e Zhang (2017) ressaltam que a governança corporativa pode influenciar também o aumento da evidenciação voluntária de natureza socioambiental.

Cabe destacar que a origem dos debates sobre governança corporativa remete a conflitos inerentes à divergência entre os interesses de sócios, executivos e o melhor interesse da empresa (IBGC, 2009). Em relação a essas questões, Moura (2014) menciona que a propriedade familiar, normalmente caracterizada como grande acionista, detentora de altos percentuais de ações (quase sempre majoritária), é um interessante mecanismo interno, em ambientes institucionais frágeis, para reduzir os custos de agência, uma vez que famílias têm mais incentivos para manter um controle eficaz e assegurar a maximização do desempenho.

Nas empresas familiares, organizações em que os controles estão vinculados direta ou indiretamente às pessoas ligadas por laços familiares, a governança corporativa está na forma da gestão dessas empresas, na necessidade de ampliação e captação de investimentos. Assim, para que as boas práticas de governança sejam devidamente aplicadas e surtam os efeitos pretendidos, os entes familiares devem compreender as características da própria empresa (SETIA-ATMAJA; TANEWSKI; SKULLY, 2009).

Um aspecto relevante para evitar conflitos e implantar uma adequada aceitação ao funcionamento de órgãos de governança e de fóruns específicos para tratativa dos conflitos é a clara distinção entre os aspectos da família, da propriedade e da gestão pelos membros familiares da empresa (CARVALHOSA, 2008).

No tocante à relação entre governança e evidenciação ambiental voluntária no Brasil, apesar de o interesse ser crescente, ainda constitui um tema cujas pesquisas apresentam resultados bastante divergentes, evidenciando lacunas que merecem atenção. Macêdo et al. (2013), por exemplo, analisaram a relação entre governança e evidenciação ambiental voluntária em uma amostra composta pelas cinco maiores empresas de cada setor econômico da BM\&FBovespa no ano de 2009 e verificaram uma correlação positiva e significativa. Porém, Santana et al. (2015), ao examinarem a mesma relação em uma amostra composta por 114 empresas não financeiras listadas na 
BM\&FBovespa nos anos de 2012 e 2013, constataram que a adoção de práticas de governança corporativa estava associada a um baixo disclosure socioambiental.

Considerando esse contexto, busca-se uma resposta para a seguinte questão de pesquisa: qual a influência da governança corporativa na evidenciação voluntária de natureza socioambiental em empresas familiares e não familiares listadas na BM\&FBovespa? O objetivo do estudo consiste em analisar tal influência.

O estudo se justifica tanto em termos de práticas empresariais como de investigações na perspectiva teórica, particularmente no que concerne às diferenças entre empresas familiares e não familiares. Embora a literatura sobre governança e evidenciação ambiental esteja crescendo, ainda há lacunas de pesquisa, principalmente no Brasil e, especificamente, em empresas familiares. Assim, o estudo contribui para essas lacunas de pesquisa, além de destacar a relevância das análises em empresas familiares.

\section{REFERENCIAL TEÓRICo}

Nesta seção apresenta-se o referencial teórico da pesquisa, que servirá de sustentação para o desenvolvimento do estudo empírico. Inicia-se abordando o tema evidenciação socioambiental. $\mathrm{Na}$ sequência, trata-se da governança corporativa, empresas familiares e não familiares. Por fim, apresentam-se estudos anteriores similares que investigaram a relação entre governança e evidenciação voluntária ambiental.

\subsection{Evidenciação socioambiental}

As ações voltadas para questões socioambientais têm aumentado significativamente nos últimos anos, refletindo a crescente preocupação das empresas com questões econômicas, sociais e ambientais (SAMPAIO et al., 2012). Ao longo das últimas décadas, a comunicação de caráter socioambiental tem despertado o interesse não só dos acionistas, que cada vez mais exigem informação dessa natureza para a tomada de decisão, mas também de pesquisadores na área de contabilidade social e ambiental, em particular na linha de evidenciação de informações (MONTEIRO; FERREIRA, 2007). O que se espera é que a avaliação da evidenciação de informação 
socioambiental seja um instrumento capaz de apoiar a gestão empresarial (SAMPAIO et al., 2012).

Essas informações são fundamentais para a empresa demonstrar aos seus usuários o que está sendo feito para ajudar e manter o bem-estar da sociedade e do meio ambiente, indiferentemente se são voluntárias ou não (LINS; SILVA, 2009). Dessa forma, a não evidenciação tornou-se um aspecto desvantajoso para a imagem da empresa no que se refere à competitividade, uma vez que aquela preocupada em valorizar sua relação com o meio ambiente conquista uma reputação diferenciada perante a opinião pública (SAMPAIO et al., 2012).

Ribeiro (2005) observa que além de a empresa seguir medidas voltadas à qualidade ambiental, é preciso que estas sejam evidenciadas para que suas ações sejam refletidas e para a sociedade assumir o papel fiscal de controle e acompanhamento. Contudo, a informação relativa à qualidade socioambiental pode ao mesmo tempo beneficiar ou prejudicar a imagem corporativa, pois, ao captar recursos do meio ambiente, sejam renováveis, sejam não renováveis, a organização utiliza-se do patrimônio da humanidade, o que muitas vezes é prejudicial.

Portanto, cabe às organizações disponibilizarem informações e relatórios com evidências coerentes de práticas e procedimentos que garantam resultados transparentes das atividades econômicas, apresentando medidas satisfatórias de desempenho econômico combinadas com resultados aceitáveis de práticas socioambientais (SAMPAIO et al., 2012).

Um importante fator que pode influenciar a evidenciação de informações de natureza socioambiental é a governança corporativa, conforme destacam uma série de estudos anteriores como Cong e Freedman (2011), Kock, Santaló e Diestre (2012), Rupley, Brown e Marshall (2012), Macêdo et al. (2013), Iatridis (2013), Bernardi e Stark (2016), Tan Habibullah e Tan (2017) e Liu e Zhang (2017).

\subsection{Governança corporativa}

Ao longo do século XX, a economia de diferentes países tornou-se cada vez mais marcada pela integração aos dinamismos do comércio internacional, assim como pela expansão das transações 
financeiras em escala global. Nesse contexto, as companhias foram objeto de sensíveis transformações, uma vez que o acentuado ritmo de crescimento de suas atividades promoveu uma readequação de sua estrutura de controle, decorrente da separação entre a propriedade e a gestão empresarial. A origem dos debates sobre governança corporativa remete a conflitos inerentes à propriedade dispersa e à divergência entre os interesses de sócios, executivos e o melhor interesse da empresa (IBGC, 2009).

Segundo o Instituto Brasileiro de Governança Corporativa (IBGC, 2009, p. 19), "governança corporativa é o sistema pelo qual as organizações são dirigidas, monitoradas e incentivadas, envolvendo os relacionamentos entre proprietários, conselhos de administração, diretoria e órgãos de controle". La Porta et al. (2000) afirmam que se trata do conjunto de mecanismos que protegem os investidores externos da expropriação pelos internos (gestores e acionistas controladores).

Conforme Paxon e Wood (2001, p. 128), “a expressão governança corporativa refere-se às regras, procedimentos e administração dos contratos de uma empresa com seus acionistas, credores, empregados, fornecedores, clientes e autoridades governamentais". Para a Comissão de Valores Mobiliários (CVM, 2002, p. 1), “[...] governança corporativa é o conjunto de práticas que tem por finalidade otimizar desempenho de uma companhia ao proteger todas as partes interessadas, tais como investidores, empregados e credores, facilitando o acesso ao capital". Complementa também que "a análise das práticas de governança corporativa aplicada ao mercado de capitais envolveria, principalmente: transparência, equidade de tratamento dos acionistas e prestação de contas".

A evidenciação ou disclosure, de acordo com Iudícibus (2004, p. 81), é essencial, pois "[...] está ligada aos objetivos da contabilidade, ao garantir informações diferenciadas para os vários tipos de usuários". Dessa forma, pode-se dizer que os mecanismos de governança corporativa interferem diretamente na evidenciação, incluindo a ambiental, por se tratar de um dos principais pilares para a tomada de decisão dos gestores das empresas, sejam familiares, sejam não familiares. 


\subsection{EMPRESAS FAMILIARES E NÃO FAMILIARES}

Superando o conceito mais restrito e primitivo de empresa, vista como uma organização de produção com o objetivo de lucro que atua em determinado mercado, Requião (2005) a descreve como uma repetição de atos, uma organização de serviços que explora o trabalho alheio, de cunho material ou intelectual.

Mendonça (2000, p. 561) apresenta um conceito mais moderno, considerando que:

Empresa é a organização técnico-econômica que se propõe a produzir mediante a combinação dos diversos elementos, natureza, trabalho e capital, bens ou serviços destinados à troca (venda), com a esperança de realizar lucros, correndo os riscos por conta do empresário, isto é, daquele que reúne, coordena e dirige esses elementos sob sua responsabilidade.

As empresas, considerando seu aspecto negocial, dividem-se em sociedades simples e empresárias. O que as diferencia não é o lucro e, sim, a maneira como a sociedade explora o seu objeto. Se o objeto social for explorado sem a organização dos fatores de produção, esta será simples, caso contrário, são sociedades empresárias.

Empresas familiares são geralmente classificadas como as que têm uma família no controle, em termos de direito de voto. Já as não familiares são aquelas cujos participantes não possuem nenhum vínculo familiar. De modo mais específico, segundo Bornholdt (2005, p. 15), empresas familiares são “[...] aquelas cujas organizações e administração estão sob o comando dos próprios sócios da família ou grupos familiares". Uma empresa possui estrutura de propriedade familiar quando há a presença de um indivíduo ou um grupo de pessoas ligadas por laços de sangue ou casamento, com participações de propriedade de grandes dimensões (CLAESSENS et al., 2002).

Para La Porta, Lopez de Silanes e Shleifer (1999), a estrutura de propriedade pode ser definida como familiar quando um indivíduo ou uma família é o acionista controlador, seja de forma direta, seja indireta. Uma empresa familiar também pode ser considerada como "aquela que tem sua origem e sua história vinculadas a uma família; ou ainda, aquela que mantém membros da família na administração 
dos negócios" (BERNHOEFT, 1987, p. 29). Lodi (1998, p. 6) afirma que a empresa familiar "[...] é aquela em que a consideração da sucessão da diretoria está ligada ao fator hereditário e onde os valores institucionais da firma identificam-se com um sobrenome de família ou com a figura de um fundador".

A empresa familiar possui três características específicas: a propriedade ou o controle sobre ela; o poder que a família exerce sobre ela; e a intenção de transferi-la às futuras gerações, considerando membros dessa nova geração na empresa (GALLO, 2004). O Banco Mundial (WORLD BANK, 2009, p. 132) observa que, apesar de apresentar diversas vantagens, as empresas familiares também enfrentam dificuldades para obter a confiança dos investidores e dar sustentabilidade de longo prazo aos negócios, apontando que "o principal desafio da governança corporativa das empresas familiares refere-se à camada adicional de relacionamentos que a família controladora / proprietária traz para o negócio".

Kenyon-Rouvinez e Ward (2004) afirmam que as empresas familiares agregam não só financeiramente, mas também em termos de duração. Dessa forma, apesar dos "conflitos" familiares, elas duram, em média, muito mais tempo do que as não familiares, vítimas das ondas de fusão e aquisição. Porém, as famílias precisam compreender que, para dar continuidade à empresa, necessitam superar diversos desafios como: a sucessão, a viabilidade do negócio, a harmonia familiar, os acionistas responsáveis e unidos. Sendo assim, o fundador empreendedor não deixa somente para os descendentes uma herança patrimonial, mas também uma situação que os torna sócios de uma empresa e membros de uma família empresária. "Quanto mais forte o senso de família, mais os membros deste grupo se sentem obrigados uns para com os outros" (DAVIS, 2006, p. 1).

O Quadro 1 apresenta um comparativo das principais diferenças entre empresas familiares e não familiares. 
Quadro 1: Empresa familiar $x$ empresa não familiar

\begin{tabular}{|l|l|}
\hline Empresa familiar & Empresa não familiar \\
\hline O objetivo é a continuidade & $\begin{array}{l}\text { O objetivo é maximização do va- } \\
\text { lor das ações, em curto prazo }\end{array}$ \\
\hline $\begin{array}{l}\text { A meta é a conversão dos ativos e } \\
\text { do prestígio da família controladora }\end{array}$ & $\begin{array}{l}\text { A meta é a satisfação das expecta- } \\
\text { tivas dos acionistas }\end{array}$ \\
\hline $\begin{array}{l}\text { A crença fundamental é de que é } \\
\text { prioridade proteger a empresa dos } \\
\text { riscos }\end{array}$ & $\begin{array}{l}\text { A crença fundamental é de que } \\
\text { um risco maior promete rendi- } \\
\text { mentos maiores }\end{array}$ \\
\hline $\begin{array}{l}\text { A orientação estratégica é a adap- } \\
\text { tação }\end{array}$ & $\begin{array}{l}\text { A orientação estratégica é o cres- } \\
\text { cimento constante }\end{array}$ \\
\hline $\begin{array}{l}\text { Os interesses mais importantes são } \\
\text { os clientes e os funcionários }\end{array}$ & $\begin{array}{l}\text { Os interesses mais importantes } \\
\text { são os acionistas e gestores }\end{array}$ \\
\hline $\begin{array}{l}\text { A empresa enxerga-se como uma } \\
\text { instituição social }\end{array}$ & $\begin{array}{l}\text { A empresa enxerga-se como um } \\
\text { ativo descartável }\end{array}$ \\
\hline A liderança é a administração & A liderança é o carisma pessoal \\
\hline
\end{tabular}

Fonte: NAJJAR (2011, p. 17).

Analisando o Quadro 1 percebe-se que a probabilidade de uma empresa familiar dar certo é maior do que de uma não familiar. Porém, quando não respeitadas, as questões familiares podem atrapalhar o crescimento e o fortalecimento dela.

\subsection{Estudos correlatos}

Nesta subseção são descritos alguns estudos similares que também analisaram questões relacionadas à responsabilidade socioambiental e à governança corporativa. Inicia-se pela pesquisa de Cong e Freedman (2011), que examinaram a relação entre boas práticas de governança corporativa, desempenho ambiental e evidenciação ambiental em uma amostra de 50 empresas que estavam entre os principais emissores de poluições tóxicas dos Estados Unidos. Os dados referiam-se ao período de 2003 a 2005 e os achados indicaram que não havia relação entre a boa governança e o bom desempenho ambiental. Mas, a boa governança estava positivamente relacionada com a evidenciação ambiental. Concluíram que os relatórios apresentados sobre o desempenho ambiental eram melhores do que o resultado real. 
Rupley, Brown e Marshall (2012) investigaram a relação entre alguns aspectos específicos de governança corporativa e a qualidade da divulgação ambiental voluntária em uma amostra composta por 127 empresas americanas, extraídas do Dow Jones Global Index, no período de 2000-2005. Ao final ficou demonstrado que a independência do conselho, a diversidade de gênero e a especialização dos membros dele estão associados com maior divulgação ambiental voluntária. Concluíram que os resultados foram consistentes com a noção de que a boa governança leva a maior transparência.

Iatridis (2013) investigou a relação entre qualidade de divulgação ambiental e governança corporativa em 529 empresas listadas na Bolsa de Valores da Malásia entre 2005 e 2011. Os resultados do estudo mostraram que a divulgação ambiental estava positivamente relacionada com a governança corporativa. Concluíram que as companhias que divulgavam informações ambientais de alta qualidade possuíam uma governança corporativa efetiva, por isso enfrentavam menos dificuldades no acesso aos mercados de capitais.

Macêdo et al. (2013) analisaram, no ano de 2009, a relação entre governança e evidenciação ambiental voluntária em uma amostra composta pelas cinco maiores empresas de cada setor econômico da BM\&FBovespa, totalizando 50 companhias. Ficou demonstrada uma correlação positiva e significativa entre a evidenciação ambiental voluntária e as práticas de governança corporativa. Diante disso, concluíram que a adoção de um conjunto maior de práticas de governança corporativa contribuía para o aumento da evidenciação de informações voluntárias relacionadas às práticas ambientais nas empresas analisadas.

Santana et al. (2015) examinaram a relação entre a evidenciação socioambiental e as práticas de governança corporativa em uma amostra composta por 114 empresas não financeiras listadas na BM\&FBovespa nos anos de 2012 e 2013. Os resultados deixaram claro que a alta adoção de práticas de governança corporativa estava associada a uma baixa evidenciação socioambiental, revelando uma contradição com o princípio da transparência, pilar da governança corporativa.

Bomfim, Teixeira e Monte (2015) analisaram a relação do disclosure da sustentabilidade com algumas características de governança 
corporativa em 76 empresas listadas no IBRX-100 da BM\&FBovespa entre 2009 e 2011. Os resultados encontrados demonstraram que a administração familiar, a idade da companhia, a influência da comunidade, a presença de um comitê de sustentabilidade, o tamanho e o desempenho apresentaram efeito positivo no disclosure da sustentabilidade. Por outro lado, a participação no Novo Mercado da BM\&FBovespa mostrou-se negativamente relacionada com o nível disclosure da sustentabilidade

Tan, Habibullah e Tan (2017) avaliaram a relação entre governança corporativa e responsabilidade ambiental em 114 empresas ligadas ao turismo de diferentes países no período de 2005 a 2013, que apresentavam dados disponíveis no banco de dados DataStream. A base de dados DataStream contém séries históricas relativas a dados econômicos e financeiros para 175 países. Os resultados demonstraram que o tamanho e a independência do conselho influenciavam o aumento da responsabilidade ambiental. Concluíram que os mecanismos de governança são elementos importantes para o envolvimento de firmas relacionadas ao turismo nas práticas ambientais.

Liu e Zhang (2017) investigaram a relação entre governança corporativa e divulgação de informações de responsabilidade socioambiental em empresas chinesas entre 2008 e 2014. A amostra foi composta por 77 empresas em 2008, 81 (2009), 181 (2010), 217 (2011), 214 (2012), 71 (2013) e 127 (2014). Do ponto de vista da governança corporativa, os resultados revelaram que a proporção estatal de participação acionária, o número de diretores, o número de reuniões do conselho de administração e a proporção de participação dos administradores estavam positivamente correlacionados com o nível de divulgação de informações de responsabilidade socioambiental. Os autores concluíram que um alto nível de governança corporativa é favorável para a obtenção de legitimidade, bem como para a divulgação de informações de responsabilidade socioambiental.

Percebe-se que os resultados dos estudos internacionais sugerem que a governança corporativa influencia o nível de evidenciação ambiental. No entanto, nas pesquisas nacionais, essa conclusão ainda não está consolidada, pois os achados são divergentes. Assim, permanece uma lacuna a qual essa pesquisa pretende contribuir para esclarecer. 


\section{Procedimentos metodológicos}

Para atender ao objetivo proposto foi realizada pesquisa descritiva, conduzida por meio de análise documental e de abordagem quantitativa. A população da pesquisa compreendeu as companhias abertas, familiares e não familiares, listadas na Bolsa de Valores, Mercadorias e Futuros de São Paulo (BM\&FBovespa). As empresas que não possuíam informações necessárias para todas as variáveis utilizadas foram excluídas da amostra, assim como as do setor financeiro, em razão das peculiaridades a elas inerentes.

A Tabela 1 apresenta como se definiu a amostra a partir das empresas que estão listadas na BM\&FBovespa.

Tabela 1: Amostra a partir da população

\begin{tabular}{l|l}
\hline $\begin{array}{l}\text { Total de empresas listadas na BM\&FBovespa (exceto do setor } \\
\text { financeiro) }\end{array}$ & 417 \\
\hline Número de empresas no relatório & 160 \\
\hline Empresas com relatórios anuais e/ou de sustentabilidade & 85 \\
\hline $\begin{array}{l}\text { Empresas com relatórios anuais e/ou de sustentabilidade modelo } \\
\text { GRI/2015 }\end{array}$ & 75 \\
\hline Empresas com dados para todas as variáveis da pesquisa & 64 \\
\hline
\end{tabular}

Fonte: Dados da pesquisa.

Dentre as 64 empresas que compõem a amostra, 22 foram classificadas como familiares. Para isso, foi identificado o tipo de estrutura de propriedade de cada uma delas. Sendo assim, quando o último acionista controlador era uma família ou um indivíduo (em termos de direitos de voto), com participação mínima de 10\%, assim como definiu La Porta, Lopez-de-Silanes e Shleifer (1999), a empresa foi considerada familiar.

Inicialmente, foi analisada a evidenciação voluntária de natureza socioambiental, por meio do constructo desenvolvido a partir das recomendações da Global Reporting Initiative (GRI), versão 4, composto por 150 indicadores de desempenho, divididos em três dimensões: econômica, ambiental e social. Os indicadores da dimensão econômica estão subdivididos nos aspectos: econômico, presença 
no mercado, impactos econômicos indiretos e práticas de compra. Os indicadores da dimensão ambiental subdividem-se nos aspectos: materiais, energia, água, biodiversidade, emissões, efluentes e resíduos, produtos e serviços, conformidade, transporte, geral, avaliação ambiental de fornecedores e mecanismos de queixas e reclamações relativas a impactos ambientais. Por fim, os indicadores da dimensão social estão subdivididos em três subcategorias: práticas trabalhistas e trabalho decente; sociedade; responsabilidade pelo produto.

Os dados socioambientais foram coletados nos relatórios anuais e/ou de sustentabilidade modelo GRI e nos formulários de referência, ambos concernentes ao exercício de 2014. Também foram obtidas informações nas demonstrações financeiras do exercício findo em 2014 encontradas nos websites da BM\&FBovespa e das empresas, além de informações financeiras coletadas no banco de dados Economática.

Ressalta-se que essa forma de avaliação da evidenciação voluntária de natureza socioambiental, por meio de índices elaborados com base nas diretrizes da GRI, já foi realizada por outros pesquisadores, a exemplo de Rupley, Brown e Marshall (2012), Iatridis (2013) e Santana et al. (2015).

Como proxy para governança corporativa foi utilizado o Índice de Ações com Governança Corporativa Diferenciada (IGCX) da BM\&FBovespa. O IGCX é um índice que, de acordo com a BM\&FBovespa (2015), “[...] tem por objetivo medir o desempenho de uma carteira teórica composta por ações de empresas que apresentem bons níveis de governança corporativa. Tais empresas precisavam ser negociadas no Novo Mercado ou estar classificadas nos Níveis 1 ou 2 da BM\&FBOVESPA". Então, foi criada uma variável categórica que recebeu valor " 1 ", quando a empresa da amostra estava listada no IGCX, e " 0 ", caso contrário.

A Tabela 2 apresenta a variável dependente, as independentes e demais variáveis de controle utilizadas no estudo. 


\begin{tabular}{|c|c|c|c|}
\hline $\begin{array}{l}\text { VARIÁVEL } \\
\text { DEPENDENTE }\end{array}$ & MÉTRICA & FONTE DE DADOS & AUTORES DE BASE \\
\hline $\begin{array}{l}\text { Evidenciação } \\
\text { socioambiental }\end{array}$ & $\begin{array}{l}\text { Índice baseado nos indica- } \\
\text { dores sociais e ambientais } \\
\text { da GRI, versão } 4 \text {, em que se } \\
\text { atribuiu } 1 \text { para as informa- } \\
\text { ções evidenciadas e } 0 \text { para } \\
\text { as informações não eviden- } \\
\text { ciadas }\end{array}$ & $\begin{array}{l}\text { Relatórios anuais e/ou de } \\
\text { sustentabilidade, modelo } \\
\text { GRI. Formulários de } \\
\text { referência. } \\
\text { Demonstrações finan- } \\
\text { ceiras. Banco de dados } \\
\text { Economática. }\end{array}$ & $\begin{array}{l}\text { Rupley, Brown e Mar- } \\
\text { shall (2012); } \\
\text { Iatridis (2013); } \\
\text { Santana et al. (2015) }\end{array}$ \\
\hline $\begin{array}{l}\text { VARIÁVEL IN- } \\
\text { DEPENDENTE }\end{array}$ & MÉTRICA & FONTE & AUTORES DE BASE \\
\hline $\begin{array}{l}\text { Governança } \\
\text { corporativa }\end{array}$ & $\begin{array}{l}\text { Variável categórica que } \\
\text { recebeu valor " } 1 \text { ", quando a } \\
\text { empresa da amostra estava } \\
\text { listada no IGCX, e " } 0 \text { ", caso } \\
\text { contrário }\end{array}$ & BM\&FBovespa & $\begin{array}{l}\text { Bomfim, Teixeira e } \\
\text { Monte (2015); } \\
\text { Liu e Zhang (2017); } \\
\text { Tan, Habibullah e Tan } \\
\text { (2017) }\end{array}$ \\
\hline $\begin{array}{l}\text { VARIÁVEIS DE } \\
\text { CONTROLE }\end{array}$ & MÉTRICA & FONTE & AUTORES DE BASE \\
\hline Tamanho & $\begin{array}{l}\text { Logaritmo natural do ativo } \\
\text { total }\end{array}$ & $\begin{array}{l}\text { Banco de dados Econo- } \\
\text { mática }\end{array}$ & $\begin{array}{l}\text { Iatridis (2013); Bernardi } \\
\text { e Stark (2016); Liu e } \\
\text { Zhang (2017); Tan, Ha- } \\
\text { bibullah e Tan (2017) }\end{array}$ \\
\hline $\begin{array}{l}\text { Concentração } \\
\text { acionária }\end{array}$ & $\begin{array}{l}\% \text { ações ordinárias em posse } \\
\text { do controlador }\end{array}$ & $\begin{array}{l}\text { Formulário de referência: } \\
\text { Seção 6.3; Seção 8.1; } \\
\text { Seção 15.2; Seção 15.4; } \\
\text { Seção 15.5 }\end{array}$ & Liu e Zhang (2017) \\
\hline Alavancagem & $\frac{\mathrm{PC}+\mathrm{PNC}}{\text { Ativo total }}$ & $\begin{array}{l}\text { Banco de dados Econo- } \\
\text { mática }\end{array}$ & $\begin{array}{l}\text { Iatridis (2013); } \\
\text { Bernardi e Stark (2016); } \\
\text { Liu e Zhang (2017) }\end{array}$ \\
\hline Auditoria & $\begin{array}{l}\text { Variável categórica que } \\
\text { recebeu valor " } 1 \text { ", quando a } \\
\text { empresa era auditada por big } \\
\text { four, e " } 0 \text { ", caso contrário }\end{array}$ & BM\&FBovespa & Iatridis (2013) \\
\hline Setor industrial & $\begin{array}{l}\text { Variável categórica que } \\
\text { recebeu valor " } 1 \text { ", quando } \\
\text { a empresa fazia parte do } \\
\text { setor industrial, e " } 0 \text { ", caso } \\
\text { contrário }\end{array}$ & $\begin{array}{l}\text { Banco de dados Econo- } \\
\text { mática }\end{array}$ & $\begin{array}{l}\text { Rupley, Brown e Mar- } \\
\text { shall (2012) }\end{array}$ \\
\hline Rentabilidade & $\begin{array}{l}\text { ROA } \\
\text { (L.L. / Ativo total) }\end{array}$ & $\begin{array}{l}\text { Banco de dados Econo- } \\
\text { mática }\end{array}$ & $\begin{array}{l}\text { Rupley, Brown e Mar- } \\
\text { shall (2012); Iatridis } \\
\text { (2013); Bernardi e Stark } \\
\text { (2016); Tan, Habibullah } \\
\text { e Tan (2017) } \\
\end{array}$ \\
\hline Idade & $\begin{array}{l}\text { Anos decorridos desde a } \\
\text { data de fundação constante } \\
\text { no registro da CVM }\end{array}$ & $\begin{array}{l}\text { Formulário de referência: } \\
\text { dados cadastrais; dados } \\
\text { gerais }\end{array}$ & $\begin{array}{l}\text { Oh, Chang e Martynov } \\
\text { (2011); Soliman, El Din } \\
\text { e Sakr (2013) }\end{array}$ \\
\hline
\end{tabular}

Fonte: Elaborada pelos autores. 
Verifica-se na Tabela 2 que a variável de evidenciação socioambiental foi classificada como dependente, e a de governança como independente. As variáveis de controle, ou seja, que também podem influenciar a evidenciação socioambiental, conforme indicado na literatura, e que também são consideradas independentes na regressão, foram:

a) Tamanho: grandes empresas atraem maior atenção dos investidores e, por isso, precisam estar atentas às questões ambientais. Portanto, espera-se uma associação positiva entre tamanho e evidenciação ambiental, conforme sugerem Iatridis (2013), Bernardi e Stark (2016), Liu e Zhang (2017) e Tan, Habibullah e Tan (2017).

b) Concentração acionária: quanto maior for a concentração acionária, maior será a possibilidade de os acionistas controladores possuírem informações privilegiadas e maiores serão os conflitos entre minoritários e majoritários. Então, espera-se uma associação negativa entre concentração acionária e evidenciação ambiental, de acordo com Liu e Zhang (2017).

c) Alavancagem: a taxa de alavancagem capta a influência dos credores na empresa; nesse caso, estes poderiam ser solidários ao risco de irresponsabilidade ambiental das empresas. Sendo assim, espera-se uma associação positiva entre alavancagem e evidenciação ambiental, conforme destacam Iatridis (2013), Bernardi e Stark (2016) e Liu e Zhang (2017).

d) Auditoria: empresas auditadas por alguma empresa de auditoria big four seriam direta ou indiretamente mais motivadas a divulgar informações ambientais relevantes e significativas, segundo Iatridis (2013).

e) Setor industrial: empresas do setor industrial são mais susceptíveis à poluição e, por isso, precisam responder mais atentamente aos investidores. Portanto, espera-se uma associação positiva entre companhias do setor industrial e a evidenciação ambiental voluntária, assim como propõem Rupley, Brown e Marshall (2012).

f) Rentabilidade: empresas mais rentáveis possuem maior lastro financeiro e, consequentemente, são mais propensas e comprometidas com a responsabilidade ambiental. Logo, também se espera uma associação positiva entre rentabilidade e evidenciação ambien- 
tal, assim como apontam Rupley, Brown e Marshall (2012), Iatridis (2013), Bernardi e Stark (2016) e Tan, Habibullah e Tan (2017).

g) Idade da companhia: empresas que atuam há mais tempo no mercado estão sujeitas a análises mais rigorosas por parte de investidores e analistas. Então, espera-se uma associação positiva entre idade da companhia e evidenciação ambiental, conforme destacado por Oh, Chang e Martynov (2011) e Soliman, El Din e Sakr (2013).

Após a definição das variáveis e da coleta dos dados, partiu-se para a análise. Inicialmente, foi realizada uma análise descritiva das variáveis de responsabilidade socioambiental, de governança e demais variáveis de controle. Para tal, foram usadas medidas de estatísticas descritivas (médias, mínimos, máximos e desvio-padrão).

Em seguida, foi feita a análise de regressão linear múltipla com vistas a verificar a influência da estrutura de propriedade na responsabilidade socioambiental. Destaca-se que se observaram os pressupostos de normalidade, por meio do teste de Kolmogorov-Smirnov; multicolinearidade, por meio do fator de inflação de variância (VIF) e Tolerance; homocedasticidade, por meio do teste de Pesarán-Pesarán; e ausência de autocorrelação serial, por meio do teste de Durbin-Watson.

\section{ANÁlise E INTERPRETAÇÃo DOS RESULTADOS}

Esta seção contém a descrição e análise dos dados coletados. Primeiramente, apresentam-se as estatísticas descritivas das informações voluntárias classificadas de acordo com as seguintes categorias: econômica, ambiental, social, de desempenho pelo total de indicadores (IE_GRI) e de desempenho por empresa (IE_EMPRESA). Em seguida, são elencados os indicadores gerais de evidenciação, segregados em empresas familiares e não familiares, bem como as informações sobre a governança corporativa. Na sequência, são evidenciadas as estatísticas descritivas das variáveis de controle, também separadas em familiares e não familiares. Por último, demonstram-se os resultados das regressões, que possibilitaram analisar o poder preditivo da variável de governança corporativa sobre a evidenciação voluntária de natureza socioambiental em empresas familiares e não familiares. Na Tabela 3 são mostrados os dados de evidenciação por categorias. 
Tabela 3: Características GRI das companhias da amostra

\begin{tabular}{l|l|l|l|l}
\hline Categorias & Mínimo & Máximo & Média & Desvio-padrão \\
\hline ECONÔMICA & 0,4844 & 0,8906 & 0,6372 & 0,1212 \\
\hline AMBIENTAL & 0,2656 & 0,7656 & 0,5483 & 0,1300 \\
\hline SOCIAL & 0,3125 & 0,8281 & 0,5360 & 0,1301 \\
\hline IE_GRI & 0,1875 & 1,0000 & 0,6138 & 0,2143 \\
\hline IE_EMPRESA & 0,2467 & 1,0000 & 0,6149 & 0,2078 \\
\hline
\end{tabular}

Fonte: Dados da Pesquisa.

Ao analisar a Tabela 3, pode-se observar que nas cinco categorias as empresas evidenciaram mais da metade dos indicadores solicitados. A categoria Econômica apresentou maior média e menor desvio-padrão, no entanto é a que engloba a menor quantidade de indicadores. Nota-se também, pelo desvio-padrão, que há uma diferença significativa entre os valores do mínimo e do máximo no indicador de desempenho pelo total de indicadores (IE_GRI) e no indicador de desempenho por empresa (IE_EMPRESA).

Todavia, nota-se que em nenhuma das categorias a média foi superior a $65 \%$. Conclui-se, dessa forma que, apesar de as empresas apresentarem os relatórios no modelo GRI, não evidenciam todos os indicadores nem atendem a eles.

A Tabela 4 mostra os indicadores gerais de evidenciação das empresas familiares e não familiares da amostra, bem como aquelas que dizem respeito à governança corporativa.

Tabela 4: Estatística descritiva do nível de evidenciação

\begin{tabular}{l|l|l|l|l|l|l|l}
\hline \multirow{2}{*}{ Empresas } & \multicolumn{2}{c}{ № } & \multicolumn{2}{c}{ Mínimo } & Máximo & Média & $\begin{array}{l}\text { Desvio } \\
\text {-padrão }\end{array}$ \\
\hline \multirow{3}{*}{ Familiares } & Listadas no IGCX & 18 & 0,30 & 0,99 & 0,55 & 0,23 \\
& Não listadas no & 4 & 0,45 & 0,77 & 0,65 & 0,14 \\
& IGCX & 22 & 0,30 & 0,99 & 0,57 & 0,22 \\
\hline \multirow{3}{*}{$\begin{array}{l}\text { Não } \\
\text { familiares }\end{array}$} & Listadas no IGCX & 24 & 0,41 & 1,00 & 0,69 & 0,17 \\
& Não listadas no & 18 & 0,33 & 0,99 & 0,63 & 0,22 \\
& IGCX & 42 & 0,33 & 1,00 & 0,66 & 0,19 \\
\hline
\end{tabular}

Fonte: Dados da pesquisa. 
É possível perceber na Tabela 4 que, entre as 22 empresas familiares da amostra, 18 encontravam-se listadas no IGCX e 4 não. Em relação às não familiares, 24 encontravam-se listadas e 18 não. As companhias listadas, por participarem dos níveis diferenciados de governança corporativa, devem ter maior compromisso com a transparência das informações ao público. Considerando as diferenças de práticas de governança corporativa entre os dois grupos (listadas e não listadas no IGCX), julgou-se interessante, também, realizar a análise descritiva de forma distinta em cada um dos dois grupos.

No tocante às empresas familiares, observa-se na Tabela 4 que, de modo geral, as não listadas do IGCX apresentaram maior média de evidenciação voluntária de natureza socioambiental $(0,65)$, no comparativo com as listadas no IGCX $(0,55)$. Portanto, as empresas que não se encontram listadas em níveis diferenciados de governança corporativa que compõem a amostra desta pesquisa evidenciaram mais informações. O desvio-padrão, superior nas empresas listadas no IGCX, demonstra que existem maiores desigualdades nos níveis de evidenciação delas.

De modo contrário, entre as empresas não familiares, aquelas listadas do IGCX apresentaram maior média de evidenciação voluntária de natureza socioambiental $(0,69)$, no comparativo com as não listadas no $\operatorname{IGCX}(0,63)$. Ou seja, aquelas que se encontram listadas em níveis diferenciados, portanto sujeitas às regras mais rígidas de governança, evidenciaram mais informações. O desvio- padrão demonstra que existem maiores desigualdades nos níveis de evidenciação das empresas não listadas no IGCX.

No geral, é possível verificar na Tabela 4 que as empresas não familiares apresentaram maior média de evidenciação voluntária de natureza socioambiental $(0,66)$, no comparativo com as contrapartes familiares $(0,57)$. Esse percentual, das não familiares, é similar ao encontrado por Macêdo et al. (2013) que analisaram, no ano de 2009, a evidenciação ambiental voluntária em uma amostra que compreendeu as cinco maiores empresas de cada setor econômico da BM\&FBovespa, totalizando 50 companhias, e encontraram um índice médio de evidenciação ambiental voluntária de $65 \%$. Também é similar ao resultado de Santana et al. (2015) que investigaram uma amostra composta por 114 empresas não financeiras listadas na BM\&FBovespa, no período de 2012 e 2013, e verificaram que, em média, elas divulgavam $65 \%$ de informações socioambientais. 
Assim como já haviam destacado Macêdo et al. (2013), continua notória a necessidade do aumento do nível de evidenciação ambiental voluntária. Somente desse modo as informações relativas a tais eventos e transações ambientais chegarão aos diversos tomadores de decisão com o grau de detalhamento necessário; caso contrário, não haverá redução da assimetria de informações no tocante às práticas ambientais.

Na Tabela 5 são apresentadas as estatísticas descritivas das variáveis de controle da pesquisa.

Tabela 5: Estatística descritiva das variáveis de controle

\begin{tabular}{|c|c|c|c|c|c|c|}
\hline Empresas & Variáveis & № & Mínimo & Máximo & Média & $\begin{array}{l}\text { Desvio } \\
\text {-padrão }\end{array}$ \\
\hline Familiares & $\begin{array}{l}\text { Tamanho (log.) } \\
\text { Concentração acionária } \\
\text { Alavancagem } \\
\text { Auditoria } \\
\text { Setor } \\
\text { Rentabilidade } \\
\text { Idade }\end{array}$ & $\begin{array}{l}22 \\
22 \\
22 \\
22 \\
22 \\
22 \\
22 \\
\end{array}$ & \begin{tabular}{|l|}
5,11 \\
25,00 \\
0,20 \\
0,00 \\
0,00 \\
0,03 \\
5,00 \\
\end{tabular} & \begin{tabular}{|l}
7,92 \\
98,23 \\
0,93 \\
1,00 \\
1,00 \\
26,73 \\
74,00 \\
\end{tabular} & $\begin{array}{l}6,77 \\
57,50 \\
0,66 \\
0,95 \\
0,27 \\
4,37 \\
35,14 \\
\end{array}$ & \begin{tabular}{|l}
0,62 \\
19,15 \\
0,20 \\
0,21 \\
0,46 \\
5,76 \\
24,12 \\
\end{tabular} \\
\hline $\begin{array}{l}\text { Não fami- } \\
\text { liares }\end{array}$ & $\begin{array}{l}\text { Tamanho (log.) } \\
\text { Concentração acionária } \\
\text { Alavancagem } \\
\text { Auditoria } \\
\text { Setor } \\
\text { Rentabilidade } \\
\text { Idade }\end{array}$ & $\begin{array}{l}42 \\
42 \\
42 \\
42 \\
42 \\
42 \\
42\end{array}$ & $\begin{array}{l}5,88 \\
10,65 \\
0,08 \\
0,00 \\
0,00 \\
0,03 \\
9,00\end{array}$ & \begin{tabular}{|l|}
8,90 \\
99,58 \\
1,08 \\
1,00 \\
1,00 \\
53,74 \\
106,00
\end{tabular} & $\begin{array}{l}7,09 \\
50,72 \\
0,60 \\
0,93 \\
0,67 \\
5,20 \\
38,12\end{array}$ & \begin{tabular}{|l|}
0,64 \\
25,36 \\
0,18 \\
0,26 \\
0,48 \\
8,41 \\
25,54
\end{tabular} \\
\hline
\end{tabular}

Fonte: Dados da pesquisa.

Observa-se na Tabela 5 que as empresas familiares da amostra se destacam com o maior percentual médio de concentração acionária, equivalente a 57,50\%, maiores indicadores médios de alavancagem $(0,66)$ e um número maior de companhias auditadas por big four (em torno de 95\%).

As companhias não familiares, no comparativo com as familiares, são maiores $(7,09)-67 \%$ delas são do setor industrial -, apresentam maior indicador médio de rentabilidade $(5,20)$ e atuam há mais tempo no mercado (38,12 anos). 
Na sequência, apresentam-se na Tabela 6 os coeficientes das duas regressões que possibilitam analisar o poder preditivo da governança corporativa sobre o nível de evidenciação voluntária de natureza socioambiental nas empresas familiares e não familiares.

Tabela 6: Coeficientes da equação da influência da governança corporativa na evidenciação voluntária de natureza socioambiental de empresas familiares e não familiares

\begin{tabular}{|c|c|c|}
\hline \multirow[b]{2}{*}{ Variáveis } & Familiares & Não familiares \\
\hline & $\begin{array}{l}\text { Coeficientes } \\
\text { (estatística t) }\end{array}$ & $\begin{array}{l}\text { Coeficientes } \\
\text { (estatística t) }\end{array}$ \\
\hline \multirow[t]{2}{*}{ (Constante) } & 0,40 & $0,58^{* *}$ \\
\hline & 0,92 & 2,11 \\
\hline \multirow[t]{2}{*}{ Governança } & $-0,05$ & 0,06 \\
\hline & $-0,78$ & 1,15 \\
\hline \multirow[t]{2}{*}{ Tamanho (log.) } & 0,08 & $-0,01$ \\
\hline & 1,55 & $-0,16$ \\
\hline \multirow[t]{2}{*}{ Concentração acionária } & $-0,01$ & $-0,01^{* * *}$ \\
\hline & $-0,85$ & $-1,68$ \\
\hline \multirow[t]{2}{*}{ Alavancagem } & $-0,53^{*}$ & 0,15 \\
\hline & $-4,35$ & 1,16 \\
\hline \multirow[t]{2}{*}{ Auditoria } & 0,02 & $-0,03$ \\
\hline & 0,17 & $-0,33$ \\
\hline \multirow[t]{2}{*}{ Setor industrial } & $0,21^{*}$ & $0,10^{* *}$ \\
\hline & 3,48 & 2,17 \\
\hline \multirow[t]{2}{*}{ Rentabilidade } & 0,03 & $0,01^{* *}$ \\
\hline & 0,70 & 1,87 \\
\hline \multirow[t]{2}{*}{ Idade } & 0,02 & $0,01^{* *}$ \\
\hline & 1,49 & 2,13 \\
\hline $\mathrm{R}^{2}$ Ajustado & 0,32 & 0,11 \\
\hline F-ANOVA & $5,87^{*}$ & $2,33^{* *}$ \\
\hline Durbin Watson & 1,96 & 2,01 \\
\hline Pesarán-Pesarán & 0,97 & 0,92 \\
\hline VIF/Tolerance & $<10$ & $<10$ \\
\hline
\end{tabular}

* Significativo a $1 \%$

** Significativo a $5 \%$

*** Significativo a $10 \%$

Fonte: Dados da pesquisa. 
Verifica-se na Tabela 6 que os $\mathrm{R}^{2}$ ajustados foram de $32 \%$ e $11 \%$. Eles são equivalentes aos registrados em outras pesquisas similares como de Liu e Zhang (2017), que apresentaram regressões com $\mathrm{R}^{2}$ ajustados de 10\%, 13\% e 32\%, de Rupley, Brown e Marshall (2012), com $\mathrm{R}^{2}$ ajustados de $14 \%, 17 \%$ e $23 \%$, e de Cong e Freedman (2011), que se basearam em regressões com $\mathrm{R}^{2}$ ajustados de $10 \%$, 14\% e $33 \%$.

Verifica-se que o teste F-ANOVA foi significante nas duas regressões, ou seja, o conjunto de variáveis independentes exerce influência sobre as variáveis dependentes. Os resultados das estatísticas de Durbin-Watson $(1,96,2,01)$ revelam que não existem problemas de autocorrelação dos resíduos, já que os valores ficaram próximos de dois. Ao se analisarem os Testes de Pesarán-Pesarán, contata-se que o pressuposto da homocedasticidade não foi violado. Por fim, verifica-se que o fator de inflação de variância (VIF) e Tolerance, nas duas regressões, apresentaram valores baixos. Portanto, nesse caso não ocorreram problemas de multicolinearidade entre as variáveis independentes dos modelos. Conforme Hair Jr. et al. (2005), um VIF é considerado alto quando está acima de dez.

Em relação à variável governança corporativa (governança), o coeficiente encontrado não apresentou significância estatística em nenhuma das duas regressões. Isso significa que o resultado difere dos registrados nos estudos de Iatridis (2013), Macêdo et al. (2013), Bernardi e Stark (2016), Tan, Habibullah e Tan (2017) e Liu e Zhang (2017), por exemplo, que constataram que a governança poderia ser vista como um conjunto de mecanismos que influenciava o aumento no nível evidenciação voluntária de natureza socioambiental. Todavia, os resultados estão alinhados aos de Santana et al. (2015), que também não identificaram influência positiva da governança no nível de evidenciação ambiental voluntária em uma amostra composta por companhias brasileiras.

O Brasil é um país (code law) que possui um mercado de ações em desenvolvimento, e a maioria das companhias possui propriedade altamente concentrada, diferente do que em mercados mais desenvolvidos, como Estados Unidos (common law), por exemplo. Sendo assim, a pressão exercida pelo acionista controlador pode estar reduzindo o impacto positivo das práticas de governança corporativa, podendo ser uma justificativa para a falta de significância identificada nesse estudo. 
Em relação às variáveis de controle, a Tabela 6 sinaliza que apenas a variável "auditoria" não foi estatisticamente significante em nenhum dos dois modelos de regressão. As variáveis "setor", "rentabilidade" e "idade" apresentaram coeficientes positivos, sempre que significativas, ao passo que "concentração acionária" e "alavancagem", quando significativas estatisticamente, evidenciaram coeficientes negativos.

No que se refere ao setor, confirmou-se que as empresas familiares e as não familiares do setor industrial podem ser mais susceptíveis à poluição, razão por que precisam responder mais atentamente aos investidores por meio da evidenciação voluntária, assim como sugerem Rupley, Brown e Marshall (2012).

Quanto à rentabilidade, os coeficientes positivos $(0,03$ e 0,01$)$ indicam que empresas mais rentáveis possuem maior lastro financeiro e, consequentemente, são mais propensas e comprometidas com a responsabilidade ambiental. Assim, nesse caso os resultados estão alinhados aos de Rupley, Brown e Marshall (2012), Iatridis (2013), Bernardi e Stark (2016) e Tan, Habibullah e Tan (2017). No entanto, o coeficiente é estatisticamente significativo apenas nas empresas não familiares.

No que tange à idade, novamente apenas dentre as não familiares o coeficiente estatisticamente positivo confirmou que aquelas que atuam há mais tempo no mercado podem estar sujeitas a análises mais rigorosas por parte de investidores e analistas. Isso explica por que divulgam mais informações ambientais, conforme destacaram os estudos de Oh, Chang e Martynov (2011) e Soliman, El Din e Sakr (2013).

Os coeficientes negativos da variável concentração acionária indicam que quanto maior ela é, maior se torna a possibilidade de os acionistas controladores possuírem informações privilegiadas e maiores são os conflitos entre minoritários e majoritários, resultando em menor nível de evidenciação ambiental voluntária, em linha com os argumentos de Liu e Zhang (2017). Todavia, ressalta-se que, outra vez, o coeficiente é estatisticamente significativo apenas no caso das empresas não familiares.

Por fim, em relação à alavancagem, o coeficiente foi estatisticamente significativo apenas entre as empresas familiares. $\mathrm{O}$ 
sinal negativo demonstra que, nesse tipo de empresa, os credores não influenciam o nível de evidenciação ambiental voluntária, conforme destacaram Iatridis (2013), Bernardi e Stark (2016) e Liu e Zhang (2017).

\section{CONCLUSões}

O objetivo do estudo foi analisar a influência da governança corporativa na evidenciação voluntária de natureza socioambiental em empresas familiares e não familiares listadas na BM\&FBovespa. Para tal, realizou-se pesquisa descritiva, documental e quantitativa em uma amostra de 64 empresas que divulgaram o relatório de sustentabilidade no modelo GRI em 2014.

Os resultados revelaram que entre as dimensões econômica, ambiental e social que compõem os indicadores recomendados pela Global Reporting Initiative (GRI), a econômica é a que possui número superior de informações divulgadas pelas empresas da amostra. De forma comparativa, no geral, verificou-se que as companhias não familiares apresentaram maior média de evidenciação voluntária de natureza socioambiental, no comparativo com as familiares.

O percentual médio de evidenciação das empresas não familiares foi similar ao encontrado em pesquisas anteriores, como a de Macêdo et al. (2013) e a de Santana et al. (2015); no caso das familiares, foi, consideravelmente, inferior. No entanto, ressalta-se que ambos os percentuais evidenciaram que as corporações familiares e as não familiares precisam evoluir, pois a evidenciação de informações socioambiental ainda está distante do ideal.

Por meio das variáveis de controle foi possível perceber que as empresas familiares da amostra se destacaram com o maior percentual médio de concentração acionária, maiores indicadores médios de alavancagem e número maior de companhias auditadas por big four. As não familiares, no comparativo com as familiares, são maiores, apresentam maior indicador médio de rentabilidade, a maioria é do setor industrial e que atuam há mais tempo no mercado.

Em relação à influência da governança corporativa no nível de evidenciação ambiental voluntária, os coeficientes das regressões não apresentaram significância estatística. Sendo assim, constatou-se que os resultados diferiram dos encontrados nos estudos de Iatridis (2013), 
Macêdo et al. (2013), Bernardi e Stark (2016), Tan, Habibullah e Tan (2017) e Liu e Zhang (2017), por exemplo, que identificaram relação positiva entre governança e nível evidenciação voluntária de natureza socioambiental. Porém, os achados estão alinhados aos de Santana et al. (2015), que também não perceberam influência positiva da governança no nível de evidenciação ambiental voluntária em uma amostra composta por companhias brasileiras.

Uma possível justificativa é que o Brasil é um país que possui mercado de ações ainda em desenvolvimento, em que a maioria das companhias possui propriedade altamente concentrada, diferente do que ocorre em mercados mais desenvolvidos, como Estados Unidos (common law), por exemplo. Desse modo, a pressão exercida pelo acionista controlador pode estar reduzindo o impacto positivo das práticas de governança corporativa na evidenciação ambiental.

Por fim, de forma complementar, verificou-se que apenas a variável "auditoria" não foi estatisticamente significante em nenhum dos dois modelos de regressão, ou seja, não influencia a evidenciação das empresas familiares nem das não familiares. As variáveis "setor", "rentabilidade" e "idade" apresentaram associação positiva, sempre que significativas, ao passo que "concentração acionária" e "alavancagem", quando significativas estatisticamente, evidenciaram associações negativas.

Os resultados despertam o interesse para novos trabalhos, daí propõe-se a ampliação do universo de pesquisa, bem como a replicação do estudo com os dados das empresas em 2015, para fins de comparabilidade dos achados. Outra recomendação diz respeito à utilização de empresas do setor financeiro, além de ser interessante também desenvolver o estudo segregando os setores, para analisar qual o nível de evidenciação ambiental em cada um.

\section{REFERÊNCIAS}

BERNARDI, C.; STARK, A. W. Environmental, social and governance disclosure, integrated reporting, and the accuracy of analyst forecasts. The British Accounting Review, 2016. [No prelo.]

BERNHOEFT, R. Empresa familiar: sucessão profissionalizada ou sobrevivência comprometida. São Paulo: IBECON, 1987. 
BOMFIM, E. T. D.; TEIXEIRA, W. D. S.; MONTE, P. A. D. Relação entre o disclosure da sustentabilidade com a governança corporativa: um estudo nas empresas listadas no Ibrx100. Sociedade, Contabilidade e Gestão, Rio de Janeiro, v. 10, n. 1, p. 6-28, 2015.

BORNHOLDT, W. Governança na empresa familiar: implementação e prática. Porto Alegre: Bookman, 2005.

MELO, M.; MENEZES, P. L. Acontece nas melhores famílias: repensando a empresa familiar. São Paulo: Saraiva, 2008.

CLAESSENS, S.; DJANKOV, S.; FAN, J. P.; LANG, L. H. Disentangling the incentive and entrenchment effects of large shareholdings. The Journal of Finance, v. 57, n. 6, p. 27412771, 2002.

CONG, Y.; FREEDMAN, M. Corporate governance and environmental performance and disclosures. Advances in Accounting, v. 27, n. 2, p. 223-232, 2011.

CVM - COMISSÃO DE VALORES MOBILIÁRIOS. Recomendações da CVM sobre governança corporativa. 2002. Disponível em: <http://www.cvm.gov.br/export/sites/cvm/decisoes/ anexos/0001/3935.pdf>. Acesso em: 19 nov. 2016.

DAVIS, J. A. Dinâmica da família empresarial. [S.1.]: Harvard Business School, 2006.

FREEDMAN, M.; JAGGI, B. An analysis of the association between pollution disclosure and economic performance. Accounting, Auditing \& Accountability Journal, v. 1, n. 2, p. 43-58, 1988.

GALLO, M. A. Ideias básicas para dirigir a empresa familiar. Baranáin: Eunsa, 2004.

HAIR JR., J. F.; ANDERSON, R. E.; TATHAM, R. L.; BLACK, W. C. Análise multivariada de dados. 5. ed. Porto Alegre: Bookman, 2005.

IATRIDIS, G. E. Environmental disclosure quality: Evidence on environmental performance, corporate governance and value relevance. Emerging Markets Review, v. 14, n.1, p. 55-75, 2013.

IBGC - INSTITUTO BRASILEIRO DE GOVERNANÇA CORPORATIVA. Código das melhores práticas de governança corporativa. 2009. Disponível em: <http://www.ibgc.org.br/ CodigoMelhoresPraticas.aspx>. Acesso em: 12 out. 2015.

IUDÍCIBUS, S. Teoria da Contabilidade. São Paulo: Atlas, 2004.

KENYON-ROUVINEZ, D.; WARD, J. L. As empresas familiares: O que são? Paris: Puf, 2004.

KOCK, C. J.; SANTALÓ, J.; DIESTRE, L. Corporate governance and the environment: what type of governance creates greener companies? Journal of Management Studies, v. 49, n. 3, p. 492-514, 2012.

LA PORTA, R.; LOPEZ-DE-SILANES, F.; SHLEIFER, A. Corporate ownership around the world. The Journal of Finance, v. 54, n. 2, p. 471-517, 1999.

LA PORTA, R.; LOPEZ-DE-SILANES, F.; SHLEIFER, A.; VISHNY, R. Investor protection and corporate governance. Journal of Financial Economics, v. 58, n. 1, p. 3-27, 2000. 
LINS, L. S.; SILVA, R. N. S. Responsabilidade sócio-ambiental ou greenwash: uma avaliação com base nos relatórios de sustentabilidade ambiental. Sociedade, Contabilidade e Gestão, Rio de Janeiro, v. 4, n. 1, p. 91-105, 2009.

LIU, X.; ZHANG, C. Corporate governance, social responsibility information disclosure, and enterprise value in China. Journal of Cleaner Production, v. 142, n. 1, p. 1075-1084, 2017.

LODI, J. B. A empresa familiar. São Paulo: Pioneira, 1998.

MACÊDO, F. F. R. R.; MOURA, G. D.; DAGOSTINI, L.; HEIN, N. Evidenciação ambiental voluntária e as práticas de governança corporativa de empresas listadas na BM\&FBovespa. Contabilidade, Gestão e Governança, Brasília, v. 16, n. 1, p. 3-18, 2013.

MENDONÇA, J. X. C. Tratado de direito comercial. Campinas: Bookseller, 2000. V. 1.

MONTEIRO, P. R. A.; FERREIRA, A. C. S. A evidenciação da informação ambiental nos relatórios contábeis: um estudo comparativo com o modelo do ISAR/UNCTAD. Revista de Gestão Social e Ambiental, São Paulo, v. 1, n. 1, p. 82-101, 2007.

MOURA, G. D. Influência da estrutura de propriedade e da gestão familiar no posicionamento em fusões e aquisições. $468 \mathrm{f}$. Tese (Doutorado em Ciências Contábeis) -Universidade Regional de Blumenau, Blumenau, 2014.

NAJJAR, E. Empresa familiar: construindo equipes vencedoras na família empresária. São Paulo: Integrare, 2011.

OH, W. Y.; CHANG, Y. K.; MARTYNOV, A. The effect of ownership structure on corporate social responsibility: Empirical evidence from Korea. Journal of Business Ethics, v. 104, n. 2, p. 283-297, 2011.

PAXON, D.; WOOD, D. Dicionário enciclopédico de finanças. São Paulo: Atlas, 2001.

PEREIRA, J. R.; PEREZ, V. V.; SANTOS, G. S.; CONSOLI, L. S.; SILVA, A. S. B. A sustentabilidade e a criação do valor compartilhado: o caso da empresa Faber Castell. Revista Científica da FEPI, Itajubá, v. 9, n.1, p. 1-5, 2016.

REQUIÃO, R. Curso de Direito Comercial. 26. ed. São Paulo: Saraiva, 2005.

RIBEIRO, M. S. Contabilidade ambiental. São Paulo: Saraiva, 2005.

ROMANO, A. L. Proposta de modelo de avaliação da sustentabilidade corporativa: as práticas no setor de cosmético brasileiro. 204 f. Tese (Doutorado em Engenharia de Produção), Universidade Metodista de Piracicaba, Santa Bárbara d'Oeste, 2014.

ROVER, S.; BORBA, J. A.; MURCIA, F. D. R.; VICENTE, E. F. R. Divulgação de informações ambientais nas demonstrações contábeis: um estudo exploratório sobre o disclosure das empresas brasileiras pertencentes a setores de alto impacto ambiental. Revista de Contabilidade e Organizações, Ribeirão Preto, v. 2, n. 3, p. 53-72, 2008.

RUPLEY, K. H.; BROWN, D.; MARSHALL, R. S. Governance, media and the quality of environmental disclosure. Journal of Accounting and Public Policy, v. 31, n. 6, p. 610-640, 2012.

SAMPAIO, M. S.; GOMES, S. M. S.; BRUNI, A. L.; DIAS FILHO, J. M. Evidenciação de informações socioambientais e isomorfismo: um estudo com mineradoras brasileiras. Revista Universo Contábil, Blumenau, v. 8, n. 1, p. 105-122, 2012. 
SANTANA, L. M.; GÓIS, A. D.; DE LUCA, M. M. M.; VASCONCELOS, A. C. Relação entre disclosure socioambiental, práticas de governança corporativa e desempenho empresarial. Revista Organizações em Contexto, São Bernardo do Campo, v. 11, n. 21, p. 49-72, 2015.

SETIA-ATMAJA, L.; TANEWSKI, G. A.; SKULLY, M. The role of dividends, debt and board structure in the governance of family controlled firms. Journal of Business Finance \& Accounting, v. 36, n. 7-8, p. 863-898, 2009.

SOLIMAN, M.; EL DIN, M. B.; SAKR, A. Ownership structure and corporate social responsibility (CSR): An empirical study of the listed companies in Egypt. 2013. Disponível em: <https://ssrn.com/ abstract=2257816>. Acesso em: 20 dez. 2016.

TAN, S. H.; HABIBULLAH, M. S.; TAN, S. K. Corporate governance and environmental responsibility. Annals of Tourism Research. 2017. [No prelo.]

WORLD BANK. Guia prático de governança corporativa: experiências do círculo de companhias da América Latina. IFC E\&S. Washington, DC: World Bank, 2009. Disponível em: <http://documents. worldbank.org/curated/en/253651468045577653/Guia-prático-de-governança-corporativa-experiências-do-círculo-de-companhias-da-América-Latina>. Acesso em: 28 fev. 2017.

Recebido em: 28-02-2017

Aprovado em: 26-04-2017

Avaliado pelo sistema double blind review.

Editor: Elmo Tambosi Filho

Disponível em http://mjs.metodista.br/index.php/roc 